\title{
SOCIEDADE - LINGUAGEM - POESIA
}

(CONTRIBUIÇÕES BIBLIOGRAFICAS RECENTES DE ORIGEM FRANCESA)

\section{Marcel Lacarra}

Sabe-se desde sempre que o homem fala, mas pareceria que apenas com Saussure entendeu-se que o homem fala do mesmo modo que cria um mito, inventa uma moda ou troca riquezas. A lingüística é considerada daqui em diante como uma das ciências do homem, e mesmo como a primeira que realmente se constituiu em ciência (a tal ponto que as outras com freqüência the pedem conselhos). Ela se acha envolvida, conjuntamente com as outras, no intenso movimento de curiosidade que as designa à atenção do público e dos editôres. Como a minha profissão me orienta para êsse setor, falarei especialmente de edições francesas e evocarei alguns livros de sociologia, de lingüística, ou situados na fronteira de uma e outra, que foram recém publicados em Paris.

Comecemos pelas "Coleções de Bôlso". O fato de um livro ou um tema entrar numa coleção dêsse tipo demonstra, sem dúvida nenhuma, a sua receptividade. Indica que um editor se pode atrever a lançar, com mais de 100.000 exemplares, (como se fôsse um romance popular), por exemplo um curso de sociologia ministrado na Sorbonne e reconstituído através de uma gravação. Ora, foi exatamente o que aconteceu com as Dix-huit Leçons sur la Société Industrielle, de Raymond Aron, um dos maiores êxitos da edição parisiense nos últimos anos, de maneira que os cursos posteriores do eminente professor tiveram que ser também editados. Essa aventura começou em 1962, sete anos mais ou menos após o início, em 1954-55, dos primeiros "Livres de Poche" (êles mesmos com quinze anos de atrase em relaçăe aos "Pocket Books" americanos). O sucesso u1trapassou tôdas as espectatival Asaim nasceu a coleção Idées da

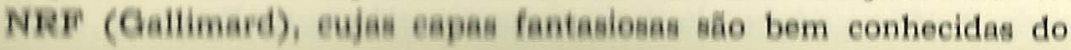


espectador dum filme recente de Godard, muito controvertido, aliás, Duas ou três coisas que sei dela. Essas capas oferecem imagens de ierpentinas ou filamentos, de tom azul claro sôbre um fundo escuro, 8 aparecem constantemente no filme - entre elas, precisamente, a das Dix-huit Leçons - ora nas mãos da heroína, ora nas prateleiras duma livraria, ora simplesmente estendidas na tela, num engrandeelmento obsessional. Os primeiros títulos da coleção foram de Camus, Eartre, Freud, Toynbee: sente-se como o editor estava tentando o publico com os nomes de mais prestígio tanto na França como no estrangeiro. $O$ ensaio pròpriamente literário tinha também que ser representado com Valéry, Breton, Claudel), mas a parte dedicada à âciologia e etnografia cresceu ràpidamente, como aparece no filme de Godard. A Sociologia do romance (Pour une Sociologie du Roman), obra prima de Lucien Goldmann, recém traduzida no Brasil, acaba de ser reeditada em Paris na coleção Idées.

Coleçóes paralelas conseguem sucesso semelhante. A muito eelática 10-18 tirou seu nome das dimensões, expressas em centímetros, dos livros que nela aparecem; oferece a todos os bôlsos, tanto Deseartes como Alexandre Dumas, tanto Mao Tse-Tung como os Quatro Evangelhos. Uma das dominantes da coleção é a difusão dos mander do Nouveau Roman: Robbe-Grillet, Beckett, Butor, MarGuerite Duras, Pinget, Simon. Importantes ensaios clássicos ou modernos aparecem também: O Príncipe de Machiavel, várias obras de Telihard de Chardin, ou, do P. de Lubac, outro jesuíta sábio, um estude penetrante sobre Nietzsche e Dostoievski intitulado Le drame de Phumanisme athée. Um dos maiores sucessos da coleção foi o admirável Tristes Tropiques, onde Claude Lévi-Strauss, o pai da aeclelegia estrutural, mistura de um modo fascinante a experiência einologica e a confidencia autobiográfica - como se pusesse em analinaf-a a objetividade do etnólogo e como se vivesse êle mesmo o drama de alsum Indio Nambikwara. Esse estudo deveria ser particularmente caro aos brasileiros: evoque êle a sua instalação na Univarialdade de să Paulo ou suas expediçōes na Amazônia, ou enumere ain ladainhas senoras os nomes de seus antigos estudantes ou de

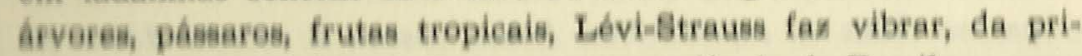
meira à ồima página do livro, a sua esperiênela do Brasil.
Achamos uma coleção já um pouco menos popular com Mediations da casa Gonthier, onde a mesma preocupação de abranger todo o humano faz com que Platão aparece ao lado de Lukàcs (A teoria do romance), e Nietzsche (A origem da Tragédia) ao lado de Max Planck (A imagem do mundo na física moderna). Boa parte dos textos publicados são de artistas que falam de sua arte, como Pierre Boulez, Paul Klee, Fernand Léger ou Serge Lifar. Com interêsse ainda maior descobrimos nessa coleção um dos mais ativos entre os representantes da Nouvelle Critique, Roland Barthes, o qual, aliás, deveríamos ver êste ano em Pôrto Alegre. Êle reeditou na Médiations, em 1965, seu célebre ensaio de 1953 Le Degré zéro de l'écriture, história da linguagem literária porquanto se indica ela mesma como literária; linguagem, por conseguinte, essencialmente privada de inocência e à qual sua evolução recente impõe um cruel dilema: "Uma obra-prima moderna é impossível", diz Barthes abruptamente nas últimas páginas: "Ou bem o objeto da obra é ingênuamente adaptado às convenções da forma,... e o mito literário não é ultrapassado; ou então o escritor reconhece a vasta pureza do mundo atual mas, para expressá-1o, êle dispõe apenas de uma língua esplêndida e morta. Entre seus dedos a História coloca um instrumento decorativo e comprometedor, uma "escrita" (une écriture) que herdou de uma história anterior diferente, da qual êle não é responsável, e que entretanto é a única que possa usar. Assim nasce um trágico da escrita..." Barthes faz seguir êsse estudo de um ensaio de sistematização da grande ciência dos signos com a qual Saussure tinha sonhado, Eléments de Sémiologie. Aí vemos a aplicação que êle faz aos diversos sistemas de significações constantemente criados pelo homem - linguagem, naturalmente, mas também modas femininas, sistemas alimentares, ordens de arquitetura, etc. - da noção saussuriana dos dois eixos da linguagem (sintagmático e paradigmático). Sôbre isso, um importante artigo de Roman Jakobson permitir-nos-á falar mais adiante. Importa assinalar entretanto os três ensaios que Barthes reuniu, em 1963, sob o título de Sur Racine. Êles deram ocasião a uma violenta tomada de posição de Raymond Picard, professor na Eerbenne e especialista de Racine, intitulada Nouvelle critique ou nouvelle imposture? (Editor: J, J. Pauvert, 1965), Barthes respondeu eom a meama violência em Critique ot vérité (Editor: Seuil,

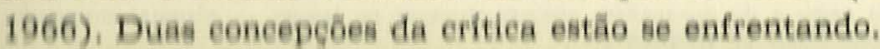


Passando às coleções de tipo clássico, infelizmente mais caras, năo mudamos de preocupações. O mesmo Gallimard das Idées lançou, em 1966, uma nova coleção de título significativo, a Bibliotheque des Sciences Humaines. Cada volume traz na $4 .^{a}$ página da eapa (atraente capa branca plastificada, com letras laranja e verde) um texto que apresenta e justifica: "...As ciências do homem invadem cada dia mais nossa cultura e nossa vida. Elas renovam nossa imagem do homem que trabalha, fala, inventa e vive em sociedade... Precisava-se de um lugar onde, longe das fronteiras tradielonais, a lingüística convivesse com a economia, o etnólogo interrogasse a psicologia e o sociólogo encontrasse o historiador". Economia e sociologia pura acumulam, de fato, numerosos títulos Arts et Peuples de l'Afrique Noire, de J. Delange; L'Egypte, impérialisme et Revolution, de J. Berque; etc. Mais próximos de nossas preocupaยอิอย, E. Benveniste, com seus Problèmes de Linguistique Générale e Milhel Foucault, com Les Mots et les Choses vão reter-nos um momento.

Michel Foucault, para começar por êle, está construindo para si, nas fronteiras da lógica, da sociologia e da história, um campo de estudos original, situando-se sua originalidade menos nessa convergênela de pesquisas que no nível de realidade ao qual êle pretende apliế=las, Ele quer ser em relação ao sociólogo o que é o geólogo em reląฺ̧̆o ao geógrafo, ${ }^{1}$ ou ainda, recorrendo à metáfora que Foucault uลa frequilentemente, o que é o arqueólogo em relação ao historiador. 1) assim como a sua Histoire de la folie à l'âge classique (mais uma obra editada em 1961 pela muito digna livraria Plon, e que passou em 1964 para a coleção de bôlso 10 -18) pretende estudar não o loueo do qual a Idade Média zomba, se bem que o aceitando, nem o deente mental que os nossos psiquiatras analisam, mas, entre os dois, 0 "insensato" dos sćculos clássicos, condenado ao trabalho forçado e muardado em asilos. Entre a inconsciencia de anteontem e a ciência de heje, que houve exatamente ontem? Nesse subsolo de nossa cullura, que esquemas perceptivos, que valóres inconfessados, que códiges fundamentais guiaram os pensamentos a as condutas?

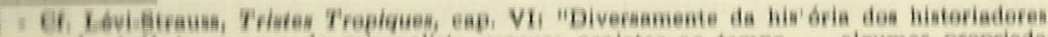

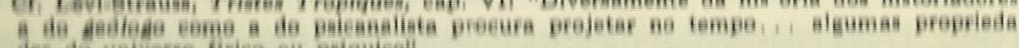

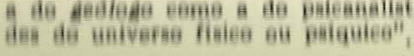

Dessa pesquisa sôbre a noção de loucura, Foucault passa, em Les Mots et les Choses, cinco anos mais tarde (1966), para uma pesquisa mais larga sôbre o universo mental em conjunto. Declara no prefácio: "Os códigos fundamentais de uma cultura (acabamos de evocá-los) . . . fixam de saída para cada homem as ordens empíricas com as quais terá que tratar e nas quais reencontrar-se-á. No outro extremo do pensamento, teorias científicas ou interpretações de filósofos explicam por que existe em geral uma ordem e a que lei geral ela obedece... Mas entre essas duas regiões tão distantes reina um campo... mais confuso, mais escuro, menos fácil de analisar. . .; entre o uso dos códigos ordenadores e as reflexões sôbre a ordem, há a experiência nua da ordem e de seus modos de ser".

Sabemos que para o autor, essas fases são datadas. Até o século XVI, existe o uso irrefletido dos "códigos ordenadores". Da Renascença até à Revolução Francesa, o Discurso toma posse do universo mental, êle permite de representar a ordem das coisas, particularmente nos três campos que Foucault considera privilegiados e em estrita harmonia: o do encadeamento das palavras na linguagem, para o qual Port-Royal inventa sua Gramática Geral; o da organização dos sêres viventes, que suscitou as grandes classificações de Buffon e de Linné; o do intercâmbio dos bens, com Adam Smith e os Fisiocratas. Assim se explicam os títulos dos capítulos da $1 .^{a}$ parte, constituindo o capítulo $3 .^{\circ}$, "Representar" uma maneira de entrada comum para os capítulos $4 .^{\circ}, 5 .^{\circ}$ e $6 .^{\circ}$, intitulados respectivamente: "Falar", "Classificar" e "Trocar".

Mas o império das palavras (Les Mots) não dura muito tempo, as coisas (Les Choses) têm sua lógica própria que, aos poucos, impõe-se à consciência. O século XIX vê aparecer na história três ciências que têm respeito ao homem, e nas quais o homem constitui-se como o seu próprio objeto de estudos: são elas a filologia, a biologia e a economia; as especulações a que anteriormente nos referimos eram apenas, em relação a essas ciências, uma pré-história. O capítulo que abre a segunda parte intitula-se "Os limites da representação", o seguinte apresenta-nos Ricardo, Cuvier e Bopp, respectivamente, como os fundadores das novas "sínteses objetivas". "O império do Discurso acabou, e, no lugar que êle deixou livre, o homem aparece", Assse homem a propósito do qual, na última 
pâgina do livro, assim se exprime o autor: "O homem é uma invenç̄o da qual a arqueologia do nosso pensamento mostra fàcilmente a data recente. E, talvez, o fim próximo."

Não será lícito falar de pessimismo e de anti-humanismo, pois que o livro admite a morte próxima da noção de homem? Em todo easo, gostaria de assinalar que tal deve ser a razão dos violentos protestos de Sartre, para quem a "arqueologia" de Foucault não é ลอกนั้ uma mistificação burguesa ao serviço do conservantismo nocial. Reciprocamente Foucault, como Lévi-Strauss, seu mestre (a quem, aliás, sucedeu algum tempo em São Paulo como professor vilitante), acusam Sartre de privilegiar indevidamente a dimensão histórica dos fenômenos sociais. Para o estruturalismo de LéviBtrauss, a inteligibilidade da história não passa de "uma ilusão que ne deve a uma situação provisória de interioridade". Admite que o homem "não pode nem deve fugir dessa interioridade. Mas a sabedoria consiste, para êle, em olhar-se enquanto a vive, sabendo bem, entretanto, (mas num outro registro) que o que está vivendo the completa e intensamente é um mito e será considerado como tal pelos homens do futuro". (La Pensée Sauvaǵ, Edit. Plon, 1962 Cap. IX: "Histoire et Dialectique"). Mas deixando para os filónefos a discussão de problemas tão essenciais, abordei os Problèmes de Linguistique Générale.

Sob êsse título, Emile Benveniste, professor na "Ecole des Hautes Etudes" e no "Collège de France" reuniu, em 1966, 28 artigos ou conferéncias dispersos até lá em revistas e atas de congressos. Aparecem distribuidos num certo número de seções, conforme os temas que a curiosidade multiforme do autor o leva a estudar: a evoluçê̆o recente das pesquisas, de Saussure aos fonólogos e a Blomfield e Hemslev (Seção I: "Transformations de la Linguistique"); problemas teóricos gerais (Seção II: "La Communication"; seção III। "Structures et analyses"); questões particulares (Seção IV: Fonetion ayntaxiques"); enfim as relaçốes delicadas entre a língua de um lado e, do outro, o universo mental e cultural do locutor (Eeçâ้อ $\mathrm{V}_{1}$ "LHomme dans la langue") seçăo VI: "Lexique et Cul(a) $\left.e^{\prime \prime}\right)$.

Multe prevelto se pode tirar dêsse livre de 350 páginas, sem

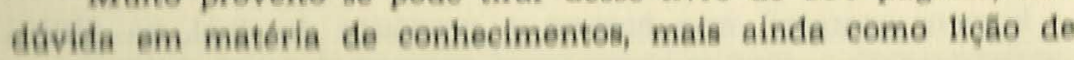

método. Fiel a êsse Método, precisamente, que Descartes batizou e que tanto tempo caracterizou o espírito francês, o autor tenta constantemente reduzir noções globais, de uso fácil mas duvidoso, a um conjunto de noções mais simples, determinadas com precisão e combinadas gradativamente de maneira a estender a zona de claridade no meio das questões mais embrulhadas. Sendo sua erudição, naturalmente, imensa, Benveniste confronta, por exemplo, as definições explícitas ou implícitas que lhe fornecem textos de Saussure, Troubetzkoi, Jakobson, Sapir, Blomfield, Harris, etc. para precisar, no capítulo $2 .^{\circ}$, a noção básica de estrutura: Uma forma lingüística constitui uma estrutura definida, explica êle, porque " $1 .^{\circ}$ : é uma unidade de globalidade abrangendo partes; $2 .^{\circ}$ : essas partes estão numa combinação formal que obedece a certos princípios constantes; $3 .^{\circ}:$. . as partes constituintes desempenham uma função; 4. ${ }^{\circ}$ : enfim, essas partes constitutivas são unidades de um certo nível, de modo que cada unidade de um nível definido é sub-unidade para o nível superior." A partir dêsse núcleo, a análise precisa-se ainda mais, mostrando como a mesma noção de "estrutura" foi interpretada em sentidos diversos dos dois lados do Atlântico; ela se interioriza mais na Europa, onde os lingüistas concebem uma solidariedade real entre as partes que entram em combinação, e também uma tendência interna a um equilíbrio, sempre ameaçado e sempre reconstituído; ela, na América, se estabelece mais ao nível do observador, o qual recusa, como teleológica, a concepção de um equilíbrio, e constata simplesmente na língua repartições de elementos e capacidades de associação e substituição.

Há, assim, questões cujos dados são esclarecidos por uma análise sistemática, até dar a impressão de uma solução definitiva; entre elas, a da comunicação animal e da "linguagem" das abelhas (capítulo 5). Seis páginas duma argumentação cerrada levam o autor a êste veredito: "O modo de comunicação usado pelas abelhas... não é uma linguagem: é, sim, um código de sinais. Daí resultam todos os seus caracteres: a fixidade do conteúdo, a invariabilidade da mensagem, a referência a uma situação única, a natureza indescomponivel do enunciado, a sua transmissão unilateral". (Fica evidente que, para Benveniste, só se pode falar de linguagem quando ae acham caracteres exatamente opostos). Mas se alguns artigos 
parecem assim fechar uma questão, outros, talvez os mais fecundos, abrem para o pensamento perspectivas inéditas. Mencionarei apenas, no capítulo 20, reflexões sôbre a natureza dos pronomes, nas quais o pronome da $3 .^{a}$ pessoa é jogado vigorosamente fora da categoria dos pessoais. De um modo parecido, no capítulo 23, Benveniste tenta definir uma nova categoria de verbos, os "delocutivos", que nh๋̆ dizem o que se está fazendo, mas o fazem dizendo-o; de maneira que o equivalente na " $10^{a}$ pessoa" da proposição "O reitor abre a porta" é que o reitor faça a ação de abrir a porta; enquanto o equivalente da proposição "O reitor abre a sessão" é que o reitor dilga "Declaro aberta a sessão". Mas não posso estender-me, e só quueria, com êstes exemplos, despertar o desejo de folhear um livro imensamente rico.

O que a Bibliothèque des Sciences Humaines representa para å ediçốes Gallimard, a coleção Arguments significa para as Editions de Minuit. Política e estética talvez estejam aí mais em evidência, eอm p. ex. Histoire et Conscience de Classe de Lukacs e Lautréamont ef Sade de Maurice Blanchot. Mas a lingüística ocupa também um lugar importante com a tradução francesa da Linguagem de Hjemslev - publicada em 1966, alguns meses depois da morte do mestre que tinha participado de sua redação e nela depositava grandes esperanças. Um pouco antes, em 1964, a coleção tinha publicado ama outra tradução fundamental, a dos Ensaios de Ingüística geral de Roman Jakobson. Evidente convergência de pontos de vista: o prefácio que N. Ruwet escreveu para esta última obra contém esta justificativa: "A lingüística é não apenas a primeira, entre as disciplinas que têm o homem como objeto, a ter elaborado uma rigorosa metodologia e a constituir-se verdadeiramente em ciência, mas, de eutre lado, os antropólogos se persuadem, cada vez mais, que a linguagem ou, de forma mais geral, a função simbólica, é a caracteifstica mais adequada para definir o homem".

A obra de Jakobson é também uma coletânea de textos esparตอร, artiges e comunicaçồ em congressos, cuja composiçăo se estende de 1949 a 1963. Na obra do grande ploneiro da fonologia, Irata ne de trabalhos de altimo periodo o americano, Sabe-se que, nascido em 1896, em Moscou, o autor e desde 1950 professor de
Lingüística Geral em Harvard e no MIT; sua movimentada carreira fê-lo sucessivamente fundador do Círculo Lingüístico de Moscou (1915) e depois do de Praga (1926), onde êle inventou a fonologia, juntamente com Troubetzkoi (1929), e, ainda, depois da invasão nazista, professor na Dinamarca e na Suécia onde apareceu uma de suas obras mais importantes (1941). Sem tentar uma análise exaustiva dos Ensaios de Lingḯistica geral, assinalarei as quatro partes em que a obra se divide: I - "Problemas gerais"; II - "Fonologia"; III "Gramática"; IV - "Poética", e retirarei ainda de dois ensaios, que me interessaram particularmente, a exposição de opiniões originais e fecundas. Trata-se do ensaio da $I .^{\text {a }}$ parte, intitulado "Dois aspectos da linguagem e dois tipos de afasia" (1956) e de outro da IV. ${ }^{2}$ parte, intitulado "Lingüistica e Poética" (1960).

A impressão fundamental é de coesão e de riqueza: alguns conceitos essenciais evidenciam-se e eis que a compreensão se faz, o caos se organiza. A precisão na análise nos seduzia em Benveniste, aqui, o poder de síntese. No ponto de partida está Saussure e a distinção de dois eixos da linguagem. No ponto de chegada encontramos, em Jakobson, a definição de dois tipos de afasia; a correlativa descoberta de duas funções da linguagem, das quais a segunda, a função poética, recebe assim uma definição que se fundamenta sòlidamente em conceitos científicos; enfim a afirmação de duas tendências essenciais na vida mental e na atividade criadora, que interferem de tôdas as maneiras para produzir as mil variedades de temperamentos, de visões de mundo, de estilos, mas que se resumem em duas, nascidas precisamente ao longo dos eixos da linguagem, afetadas precisamente nos dois tipos de afasia. Definamos logo alguns têrmos: os dois eixos da linguagem são o eixo dos encadeamentos e o eixo das substituições (diz-se também sintagmático e eixo paradigmático); as duas afasias correlativas podem ser definidas como perturbações da contigüidade e da similaridade; as duas tendências mentais seriam a tendência à metonímia e a tendência à metáfora.

A idéia de eixos na linguagem não apresenta nada de misterioso. Ela nos leva a observar que, quando falamos, os sons, as palavras se ordenam em cadeia, como fios orientados (eixo dos encadeamentos ou sintagmático ou das contigüidades) mas também que em eada ponto da cadela o fio real fol escolhido entre milhares 
de fios possíveis, tesouro sempre vivo na memória do falante (eixo das substituições ou paradigmático ou das similaridades). Assim, no nível da segunda articulação, na palavra francesa "père", o fonema "è" segue o fonema "p" e precede " $r$ "; mas êle foi escolhido num tesouro onde figuravam também os fonemas " $i$ " (o que teria resultado "pire"), "o" (que teria resultado "pore") etc. Da mesma forma, no nível da primeira articulação, um encadeamento liga a palavra "pai" a outras palavras contíguas num enunciado como "Meu pal me ordena a permanecer"; mas várias substituições eram possíveis, que teriam retirado de meu tesouro mental "tio" ou "rei" em lugar de "pai": "Meu rei me ordena a permanecer". Saussure já o tinha dito, e quase sob a mesma forma, como um dos pontos fundamentais de seu famoso Cours (1916).

Quando Jakobson, em Praga e depois na Dinamarca, começou a estudar os fenômenos ligados ao aprendizado da linguagem na crlança e, correlativamente, à sua destruição no afásico, seu passo pròpriamente genial consistiu em argumentar que o valor da explicaçlo de um esquema como aquêle dos eixos saussurianos devia aer total e envolver todo o real da linguagem.

Ora, com efeito, as observações clínicas que lhe forneciam as bras de psiquiatras convergiam para dois tipos essenciais. Em um, a perturbação da similaridade, a aptidão a encadear não é afetada $n 0$ doente, mas êle perde progressivamente o poder de procurar as palayras de substituição. Ele só sabe dizer "chove" se está chovendo. Ale repete, sem responder, a pergunta que the é feita. Em última instância, ainda que sobrevivam tôdas as palavras de indicação e de ligaçăo, pronomes, conjunções, demonstrativos, subordinantes e que subsista quase intacta a estrutura formal das frases, o conteúdo redua-1e a nada, com o uso constante de têrmos como "coisa" (ou em francês! "truc", "machin"... ) E ao contrário a estrutura formal dal frases que 8 afetada primeiramente na perturbação da contisilidade, O pronome "eu" ó o primeiro a perder-se (ele é o áltimo a ser adquirido pela criança), Vem a vez dos "que", dos "ou", dos "mas", Cheganse ràpidamente ao estilo telegráfico: conservou-se o tesoure dos termos aptos a designar os objetos, perdeu-se o poder de reunt-los
A demonstração de Jakobson é impressionante. A quem duvidar, perturbado por resultados tão surpreendentemente sistemáticos, responder-se-á primeiro que tal parece ser, com efeito, a reação inicial do leigo diante dos resultados de tôda pesquisa estrutural; em seguida, que uma confirmação importante é dada às teses de Jakobson pelo lugar de primeiro plano em que o colocam especialistas como $\mathbf{H}$. Hécaen e $\mathbf{R}$. Angelergues, ambos médicos de hospitais psiquiátricos, em uma obra técnica que se intitula Pathologie du Langaǵe. Lê-se aí, na página 102: "De grande interêsse nos parecem ser as análises das perturbações afásicas que tomam por base os dados da lingüística estrutural, tal como ela se desenvolveu desde F. de Saussure"; e em seguida apresentam longamente a teoria de Jakobson. Conviria notar aqui a obra Pathologie $d u$ Langage foi editada em 1965 na nova coleção - mais uma - de Larousse, desta vez intitulada Langue et Langage. Encontram-se na mesma coleção com elegante encadernação branca: Grammaire structurale du français de Jean Dubois (1965), Structure immanente de la langue française de Knud Togeby (1965) e Sémantique Structurale de A. J. Greimas (1966).

Voltando a Jakobson, resta-nos, saber se o tipo de destruição que causava a doença não se encontrava já prefigurado no indivíduo são pela presença de uma certa tendência: metafórica, naqueles que, a um estímulo dado, reagem de preferência por substituição (e são as perturbações de contigüidade que os ameaçarão em caso de afasia); metonímica, naqueles que reagem com maior frequiência completando e encadeando (e que ameaçam as perturbações de similaridade). E desde 1935, em Praga, que Jakobson tentou uma primeira elaboração dêstes conceitos, num artigo sôbre a poesia de Pasternak. Mas onde a teoria torna-se para nós fascinante é quando ela se aplica à determinação das seis funções da linguagem. (E onde também, infelizmente, precisaremos ser mais breves).

Três das seis funções são relativas aos três pronomes fundamentais. O falante diz "eu": função emotiva. Êle se dirige a um ouvinte, "tu": função conativa. 'Ele the fala de um contexto, "êle" ou "isto": funçăo reforencial. Uma quarta função, menos evidente, 6, aog olhos đe Jakobson, essencial: 6 a função de contato que êle 
nomeia de fática; os "alô" repetidos ao telefone a simbolizam, e ela está presente em muitos diálogos, quando o essencial parece ser, nh̆o o dizer alguma coisa, mas o manter o contato. Ao número de desenvolvimentos que estas classificações abrem do lado da estilística, eu colocaria eventuais estudos sôbre o monopólio da função referencial no Nouveau Roman, tão obsessivamente descritivo e "objectual", e sôbre a importância da função fática nos diálogos de eertos personagens de teatro, por exemplo, as larvas humanas de Deckett.

Restam-nos, finalmente, a quinta e sexta funções, a propósito das quais nós encontramos nossos dois eixos. Pois no centro de tudo está a mensagem e, para formulá-1a, um código (a língua) é utilizado. Ora pode acontecer que a mensagem, em lugar de ser um imples meio de informação, seja considerada nela mesma e tratada como tal. $\mathrm{E}$ então a função poética, que se manifesta na obra literấria certamente, mas também com muito mais freqüência, num alogan, num jôgo de palavras, etc. $\mathrm{E}$ ao preço, em todo o caso, de uma inversão notável: prendemo-nos ao fato de que as palavras se atraem umas às outras (ou os elementos de uma mesma palavra), desenvolvendo certas semelhanças (aliterações, repetições rítmicas, (mas, etc.) com as quais um enunciado normal não tem nada que ver, $\mathrm{Na}_{a}$ vordade, transportamos o princípio de semelhança do eixo de aubstituiçõos para o eixo dos encadeamentos. Inversão reciproca daquela que se realiza quando nos interessamos pelo código, em uma operaçĩo que coloca em jôgo a sexta e última função, a função metalinglilstica: função também de um uso quase constante que utiliamos na análise gramatical ou quando queremos precisar a algnificaçăo de uma palavra. Mas quando dizemos: "O centauro a um ser mitologico", transportamos o principio de contigüidade do eive dos encadeamentos ao oixo das substituições. Confesso sentir menol a fórça desta proposição que a da precedente, que me parece abrif, sôbre a essêneia da criaçăo poética, desenvolvimentos fecundos.

Ifis am todo o caso, a fórmula de Jakobson: "Na metalingua" fem, a sequibencia é utilizada para construir uma equasçăo, enquanto que na poesla é a equaçăo que serve para construir a sequiéneia", Fenso em Valéry, estruturalista sem sabê-lor "A poesla exige...

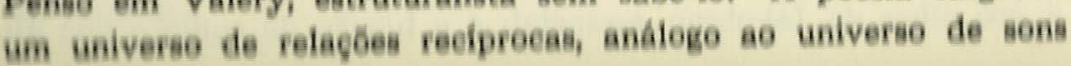

onde a forma, longe de dissolver-se no seu efeito, é como exigida por êle".

O estruturalismo tem verdadeiramente um poder integrador fascinante. Reclamando para o lingüista o direito de aplicar seus métodos no estudo da poesia, Jakobson parafraseava Terêncio e declarava: "Linguista sum, linguistici nil a me alienum puto". Mas a lição dessas leituras seria que tudo, ou quase, é "linguisticum" e que, então, muito trabalho nos espera. 